\title{
Various Sides of Empathy Literature Evokes in Medical Students
}

\author{
Paula Strengell \\ Tampere University, Finland
}

\begin{abstract}
Most studies show that medical students' capacity for empathy decreases during their studies. Personal distress, burnout and lowered quality of life are suspected causes. Doctors' empathy is an important tool in gaining anamnestic information and adherence to recommendations resulting in better clinical outcomes. Empathy is taught by a variety of methods, but utilizing literature has been rare. Quantitative methods have been used in assessing the level of and change in empathy as far as measuring the effect of interventions. Aim of this study is to gather qualitative information about the nature of emotions and reactions difficult patient encounter simulations evoke. In this case study, a group of medical students were asked about their feelings after reading autobiographies about depression or bipolar disorder. It became clear that encountering difficult patients in literature evokes conflicting emotions in students. In order to maintain empathy during medical studies, students need ways to practice different domains of it. Handling emotional reactions is as important as cognitive recognition of patients' feelings and conveying empathy to them.
\end{abstract}

\section{Introduction}

Since it is commonly viewed that empathy diminishes during medical studies, there ought to be ways to counter that decline. Empathy can be used consciously and it has been divided into three domains: cognitive, social skills and emotional reactivity. Other ways to define empathy exist, but in the medical context identifying and understanding patients' experiences and perspectives constituting the cognitive part has been considered central together with the social skills needed to convey the understanding to the patient. Imagining and sharing patients' feelings constitute the emotional involvement (sympathy) [1].

Emotions are important in gaining information about the patients' inner feelings, but the doctor should be able to separate the patients' emotions from his own to avoid overidentification. Good balance is needed between rational, fact based thinking and information gathered by emotional binding with the patient. Like Russian mountaineer
Anatoli Bokureejev has stated, "you cannot afford empathy above the base camp." Since empathy improves the clinical outcome, it has also been included in teaching objectives. In certain more technically-oriented fields of medicine empathy is not so essential [1].

Female medical students have been shown to be more empathetic and this gender difference is more prone in the affective component of empathy. On the other hand, cognitive empathetic skills seem to be only slightly more prominent among women. Selfassessed empathy does not decline with age in the general population [2]. In other demanding fields, such as law and psychology, students' moral judgement competence does not decrease during studies when measured with comparable methods. In the medical field, unrealistic expectations and high inner values conflict with the morbid and mortal reality. Towards the end of the studies, female students in particular tend to feel more emotional exhaustion and distress. Depersonalizing behavior, detachment and cynicism are other possible negative consequences that also predispose to unprofessional behavior. Hence, educators encounter the challenge of teaching emotional competence and empathy as a part of it [1, 3, 4]. Empathy is an important part of well-being and satisfactory social relationships [5]. Students need to be better prepared for the multiform psychological responses they are to encounter during their careers. Since empathy level diminishes during studies, we should try to teach students skills by which they could afford empathy even after graduation.

Whether the affective or the cognitive nature of empathy is relevant for medical students' well-being is an important topic to study. Sometimes the concept 'medical empathy' is used to refer to the special qualities of empathy needed in doctor's work. The meaning of empathy is hence twofold, it is important both for the patients' and students' best. The way educators teach empathy should take both aspects into consideration. Using empathy wisely, at least partly consciously, might be part of resilience, the adaptive capacity needed when encountering stressful or traumatic events [6].

Despite the fact that over a dozen theories of resilience exist, common features to most of them are 
personal protective factors and situational social support that help the person reintegrate after aversive events. People with high resilience appraise emotions as facilitative to functioning [6]. Positive emotions as active ingredients in resilience are important in gaining equilibrium and even post-traumatic growth after aversive events. They overweigh the impact of negative emotions on the autonomous nervous system, enhance cognitive broadening and generate resources for future [7]. Successful mastering of moderate stress results in "stress inoculation" when a person develops an adaptive stress response and will be better than averagely resilient for future uncontrollable stressors. The key influencing factor is the degree of control the person has over the stressor [8]. Emotional reactivity in empathy includes involvement both in patient's positive and negative emotions. Positive emotions are for example joy, amusement, gratitude, interest, love, serenity and contentment. Negative feelings are sadness, anxiety, fear and greediness. Sympathy is considered neutral. Categorization reflects the effect of the feeling for the person himself considering that positive feelings have the resilience promoting effect.

The Jefferson Scale of Physician Empathy is the most common self-report questionnaire used in empathy studies for medical students [9]. Initial studies suggest that results acquired by self-report scales are comparable to patient-reports without significant desirability bias. It is still unclear how well these results correspond to behavioral expressions of empathy. In Ogle's study (2013) [10] students were considered competent by patients and empathetic by observers even though students' selfratings were low. It seems rational that doctors should react differently compared to nonprofessionals in difficult situations and so forth it is important to use appropriate scales and study the relevance of different factors of the scales [11].

Empathy teaching interventions have been effective, but long term follow-up is scarce [9]. Hojat's study (2013) [3], for example, used films about patient-doctor encounters and students had the opportunity to discuss how the relationships worked. That is a cognitive action and improves the students' skills to read social situations and differentiate doctor's and patient's contribution to the situation. It still remains unclear, how the different domains of empathy interact with each other. Information is needed about the spectrum of feelings relationships with patients provoke in medical students and how they can handle them. Also the negative feelings need to be considered. Few studies have measured the power of literature or writing in strengthening empathy. Shapiro's study (2006) [12] showed that the point-of-view writing method enhanced more expressed feelings compared to clinical reasoning and also negative feelings were included. However, no benefit in standard patients' reviews about "the doctor's" empathy was noticed.

\section{Methods}

To provide the students an emotional experience about depression, literature has been used in teaching at The School of Medicine at Tampere University. The book chosen was William Styron's Darkness visible (1990). Focus has been on the students' own feelings the book arouse. In the last five years selection has widened to Kay Redfield Jamison's An Unquiet mind (1995) as well as movies and writing an essay from the viewpoint of one character in the book.

In group discussions four pre-answered questions are touched: what feelings reading the book evoked in you, how well did the description of the illness correspond to your own supposition, how do you imagine the spouse felt and how do you reflect the patient-doctor relationship. Students have time to talk in small groups with each other about the topics one at a time and a general discussion follows. Anonymous answers are gathered. The students take part in a three week course which includes lots of psychiatry and general medicine. Topics like doctor's own coping skills and burnout are processed. In this study answers for the first question concerning students' own feelings (2014 and 2015 student groups) are analyzed by study-specific theme typology of feelings to make subtle individual differences visible. Different types of feelings are gathered in larger categories of positive (gratitude, knowledge, respect), negative (annoyance, anxiety, envy, sadness, surprise) and neutral (sympathy, none) feelings (Table 1). Only the book reading groups are involved. Answers are written in a free format, postulating that so also the conflicting and more controversial sides of medical students' ideas about difficult patients are revealed.

Later another analysis comparing the answers for the direct question about the students' own feelings (reflecting the emotional involvement or sympathy) to those reflections they have about the spouse's feelings (cognitive skill) will offer an opportunity to declare means to detect empathy indirectly. Answers to inquiries about the depression symptoms and patient-doctor relationship indicate the student's evaluation of his competence and social skills.

\section{Results}

"Extraordinarily annoying questions. Try make better in the future."

Results of the students' reflections about their feelings concerning Kay Redfield Jamison's book about her own bipolar disorder can be categorized as follows. Answers of 26 students during fall 2014 and 
2015 have been evaluated, median age is 23 and the sample includes six males.

Gratitude (3): Three students express gratitude for their own mental wellbeing.

Knowledge (13): The reading experience acted as an eye-opener to some students who were surprised of the multiform symptoms of bipolar disorder and that enhanced them craving for more knowledge and studying the subject in detail. Especially the fact that many mentally ill patients do not take their medication got better understood.

Respect (8): Students found it respectful that the patient could go on even with a severe mental illness. Since the author is a mental health professional, she was reckoned clever and skillful in her descriptions. It was comforting that the author felt hopeful after all.

Annoyance (2): Two comments told about getting annoyed about the patient's attitude. The students felt that the author mystified the difficult sickness and appraised it too positively.

Anxiety (10): Ten comments include anxiety, insecurity, fear, confusion and shock. "Being the slave of your own psyche is horrifying." "Chaotic since I have yet so little knowledge about mental illnesses." It was also scary that the patient's own perception of her condition differed radically from other people's views. "Could not avoid thinking what if I fall ill myself."

Envy (5): Five comments showed jealousy about the patients' colorful mental life and intensive feelings. Someone might even want to experience it himself. Kind of amusement about the manic person's awkward behavior was also expressed.

Surprise (5): For some students it was quite puzzling to arrange their feelings into any words, they got bewildered. It was difficult to see how someone can live quite normally with such a severe disease.

Sympathy (6): Six comments can be categorized as sympathy; wordings like sorrow and compassion are used in addition to empathy.

None (6): Six comments said that no feelings were aroused. "You cannot realize it if you do not experience it yourself."

39 students' (25 female and 14 male) responses after having read Darkness visible, median age 24:

Gratitude (3): for the fact that the illness does not concern you, feeling relieved for yourself and also for the patient who did not commit a suicide.

Knowledge (7): curiosity and notion that there is not enough knowledge about treatment. Someone reflected his own melancholic feelings to those of the patient's pondering the difference between normal and perturbation.

Respect (5): feeling hopeful and able to find a solution, patient being a good example.
Annoyance (6): patient's incriminating ideas against care givers were felt as annoying, the patient was seen as self-centered and canvassing readers.

Anxiety (31): anxiety was also described as restlessness, feeling helpless. One student described helplessness and feeling hopeful at the same time. Fear of getting depressed, because it can happen to anybody.

Envy (0): none.

Sad (13): feeling sad, joyless, depressed. This category did not come up in the book describing bipolar disorder. Sad for the patients' underserved needs. "Eternal darkness."

Surprise (2): "something I cannot understand", "being tired".

Sympathy (16): got more understanding about the nature of depression and depressed people, especially the descriptions of suicidal intentions were powerful. Compassion.

None (10): including being bored. The text was alienating and in conclusion the depressed patient's mind cannot be understood.

\section{Discussion}

The two books are different. Both contain a happy enough ending since the protagonist does not end up committing a suicide. An Unquiet mind has ups and downs, sometimes even stable intervals. The author describes variable feelings. Darkness visible mostly describes a deep depressive state and the story becomes more hopeful only in the last pages. That difference probably explains the difference in the distribution of positive and negative feelings.

Students' emotional life seems sometimes to be in quite a turmoil when they read the book. The same person expresses opposite feelings like hopelessness and hopefulness at the same time. They can mostly see that even if the situation is sometimes horrifying, it might get better. There are no answers that would suggest trying to please the teacher or giving a certain conception of oneself. Answers are pretty plain and open. Some of them are written in elegant descriptive language like the student would be imaging himself into the author's mind. One word answers do not exist. Shortest are those saying that the book did not evoke any feelings and even in those answers the student might observe being bored. So the most prominent feature is the magnitude and variety of emotions.

Compassion was a common feeling. "Empathy" in everyday language often means compassion, sympathy and understanding all the same. Reading the students' answers as a whole it is clear that they used it in that common language meaning. Empathy as an ability to understand the patient's viewpoint, emotions and conflicting behaviors was more often expressed indirectly ("I got better understanding why the patient behaves like that. I was envious about the intensive feelings she could experience.") The 
answers included empathetic responses in both meanings.

Approximately one third of the students felt sympathy, more so in the responses on Darkness visible. One third got the urge to find out more about the disease, its medical aspects and treatment. They tried to see the reasons behind the sometimes irritable behavior of the patients. They could see that sick people are regressive and cannot control their state. At this point of their studies, beginning of the fourth year, students are just beginning to study psychiatry. They have not yet had patients on their own but have been watching specialist doctors' work and interviewed some patients under supervision. Minority of the students come into the conclusion that the severely depressed patients cannot be helped and henceforth the reading experience is predominantly anxious to them. They think that as the patient cannot consciously change his mood and attitude, so also the doctor is incapable to help him. Sometimes students get stuck to this point and cannot keep up hope and try see further. Also, it might happen that students rush to conclusions about medications ignoring the psychological aspect of the sickness. That is quite uncommon, though.

What is noteworthy is that some students expressed opposing feelings at the same time; for example one student found the patients' attitude annoying but anyway valued her ability to go on. The aim of this education method was to make students reflect their feelings without prejudgment. It is good if they can also express the kind of feelings that are easily understood as negative. Awareness of your own feelings helps acting professional.

Aversive feelings are common. Being annoyed or agitated for the patient's inconsistent and harmful behavior is freely expressed. Despite that there are no comments that would suggest an urge for unprofessional behavior - no one would leave the patient without care even though they feel puzzled what should be done. Anxiety was mostly connected to helplessness, but some students also described horror or shock. Reportedly, they did not know beforehand how strongly the disease can affect the patient and his whole life.

Negative feelings (annoyance, anxiety, envy, sad and surprise) were most common. In group discussions they were also expressed, but in a significantly lesser amount. It seems that peer pressure and the presence of a teacher produce bias. Some notions, especially about gratitude and envy, make it clear that the reading experience was very personal for most students. Those readers who emphasized gaining knowledge had less emotional content in their answers than others. One important source of anxiety in its different expressions was uncertainty of one's own competence and feeling that treating that kind of patient would be overwhelmingly difficult.
"I was surprised how positively the patient described her illness. She would choose the same illness again if there was a choice."

\section{Conclusions}

Future studies are challenged to measure the different domains of empathy. If domain specific decline exists, that could help differentiate if the phenomenon is more of compassion fatigue or cognitive by nature. That would contribute to determining the actions needed in medical education. Decline of empathy happens especially during clinical practice. Shapiro's review (2008) [13] of interventions suggests adding reflection and selfawareness into the curriculum. In addition, empathy erosion due to current teaching methods and hidden curriculum should be targeted [4]. Even these days students may describe going into the clinic as "being thrown into ice cold water and being watched if one can swim". That must be really scary if even reading a book about severe mental illness provokes such intensive feelings of incompetence. Female students restore empathy better during studies, but they are also more prone to distress. It should not be forgotten that emotional burden in doctor's work is partly a byproduct of the capacity for empathy.

A study conducted after the WTC attacks in New York showed that people with high resilience were affected by the disaster as well. They felt sorrow, fear and sympathy as much as people who suffered more distress later. However, resilient people's positive feelings (gratitude of being alive, curiosity and valuing your own life and health higher than before) helped them get over with the horrible incident better [14]. Medical students encounter mortally ill patients and yet they should be able to maintain hope and positive image of their own life as well as empathy to patients. The positive feelings need to be strengthened and that might be easier if students could view the patient as a person in his own life context, the disease not being the only determinant factor. Narrative approach may be helpful.

Supporting measures for maintaining and maybe even gaining resilience during studies might be possible. Emotion regulation is part of resilience and the ability to identify and differentiate feelings is an important part of that. Educators' concern has been focused in empathy erosion during studies. Next step is widening the scope to students' capability to handle emotions. Being able to cope with negative feelings helps avoiding depersonalization behavior. Behavioral training targeting psychosocial risk factors that inevitably belong to doctor's work could be beneficial. Positive feelings are important among better coping skills, physical health, supportive environment and other positive social factors [8]. 
Literature offers a safe and easy access for medical students to practice the full scope of empathy. Negative feelings are safe to encounter and express in that context. That is important in avoiding the fake impression that they do not exist among health care professionals. Also, since suffering patients have abundantly painful emotions, doctors should be able to receive those as well as positive emotions. The crux of ascending in the medical career is to carry out that load, avoiding crevasses of excessive emotional burden. When we give the students the tools for healing people, we should also equip them with the crevasse self-rescue skills, in this case a pocket book.

\section{Study limitations}

This is a qualitative study providing information about the nature of students' feelings. It does not tell whether using literature impacted medical students' empathy. It has been shown before that using humanistic means is able to do that. Different domains of empathy should be more precisely confined in the context of provoked feelings. It is impossible to say what kind of connection there is between different kind of feelings (positive, negative and neutral) and domains of empathy (cognitive skills, social skills and emotional reactivity). This would require a more thorough analysis of the students' answers comparing what they postulate about the spouse's or doctor's feelings versus their own. Differentiating a specific feeling requires both cognitive and emotional aspects. These results could be used as a basis for further research of using literature in teaching medicine.

\section{References}

[1] M. Hojat, J.S. Gonnella, T.J. Nasca, S. Mangione, J.J. Veloksi, and M. Magee", The Jefferson Scale of Physician Empathy: Further Psychometric Data and Differences by Gender and Specialty at Item Level", Acad Med, 2002:77(10), pp. 58-60.

[2] D. Gruhn, K. Rebucal, M. Diehl, M. Lumley, and G. Labouvie-Vief, "Empathy Across the Adult Lifespan: Longitudinal and Experience-sampling Findings", Emotion, 2008:8(6), pp. 753-765.

[3] M. Hojat, D. Axelrod, J. Spandorfer, and S. Mangione, "Enhancing and Sustaining Empathy in Medical Students", Med Teach, 2013:35, pp. 996-1001.

[4] M. Neumann, F. Edelhäuser, D. Tauschel, M.R. Fischer, M. Wirtz, C. Woopen, A. Haramati, and C.
Scheffer, "Empathy Decline and Its Reasons: A Systematic Review of Studies with Medical Students and Residents", Acad Med, 2011:86(8), pp. 996-1009.

[5] H.B.M.S. Paro, P.S.P. Silveira, B. Perotta, S. Gannam, S.C. Enns, R.R.B. Giaxa, R.F. Bonito, M.A. Martins, and P.Z. Tempski, "Empathy among Medical Students: Is There a Relation with Quality of Life and Burnout?", PLoS One 9(4):e94133. Published online 2014 Apr 4. doi: 10.1371/journal.pone.0094133, 2014.

[6] D. Fletcher, and M. Sarkar, "Psychological Resilience. A review and Critique of Definitions, Concepts, and Theory", Eur Psychol, 2013:18, pp. 12-23.

[7] I.R. Galazer-Levy, A.D. Brown, C. Henn-Haase, T.J. Metzler, T.C. Neylan, and C.R. Marmar, "Postive and Negative Emotion Prospectively Predicts Trajectories of Resilience and Distress among High Exposure PoliceOfficers", Emotion, 2013:13(3), pp. 545-553.

[8] G. Wu, A. Felder, H. Cohen, J.J. Kim, S. Calderon, D.S. Charney, and A.A. Mathe, "Understanding Resilience", Front BehavNeurosi,doi:10.3389/fnbeh. 2013.00010.eCollection2013:15(7:10).

[9] Z. Kelm, J. Womer, J.K. Walter, and C.F. Feudtner, "Interventions to Cultivate Physician Empathy: A Systematic Review", BMC Med Educ 14: 219. Published online 2014 Oct 14. doi: 10.1186/1472-6920-14-219, 2014.

[10] J. Ogle, J.A. Bushnell, and P. Caputi, "Empathy Is Related to Clinical Competence in Medical Care", Med Educ, 2013:47, pp. 824-831.

[11] M. Hojat, S. Mangione, G.C. Kane, and J.S. Gonnella, "Relationships Between Scores of the Jefferson Scale of Physician Empathy (JSPE) and the Interpersonal Reactivity Index (IRI)", Med Teach, 2005:27(7), pp. 625628.

[12] J. Shapiro, L.L. Rucker, J. Boker, and D. Lie, "Pointof-View Writing: A Method for Increasing Medical Students' Empathy, Identification and Expression of Emotion, and Insight", Education for Health, 2006:19(1), pp. 96-105.

[13] J. Shapiro, "Walking a Mile in Their Patients' Shoes: Empathy and Othering in Medical Students' Education", Philos Ethics Humanit Med, 2008:3(10), doi 1747-5341-310.

[14] B. Fredrickson, M. Tugade, C. Waugh, and G. Larkin, "What Good are Positive Emotions in Crisis? A Prospective Study of Resilience and Emotions Following the Terrorist Attacks on the United States on September 11th, 2001", J Pers Soc Psychol, 2003:84, pp. 365-376. 